\title{
Advances and Perspectives in Using Medical Informatics for Steering Surgical Robots in Welding and Training of Welders Applying Long-Distance Communication Links
}

\author{
Zbigniew Prusak¹, Ryszard Tadeusiewicz ${ }^{\circledR}$, Ryszard Jastrzebski ${ }^{3}$ and Ilona Jastrzębska ${ }^{4, *}$ \\ 1 Professor, Central Connecticut State University, New Britain, CT, USA; prusakz@ccsu.edu \\ 2 Professor, AGH University of Science and Technology, Krakow, Poland; rtad@agh.edu.pl \\ 3 Institute for Joining of Metals, Krakow, Poland; rj@ilm.pl \\ 4 Ph.D. Eng., AGH University of Science and Technology, Krakow, Poland; ijastrz@agh.edu.pl \\ * Correspondence: ijastrz@agh.edu.pl
}

Received: 02.04.2020; Accepted: 03.06.2020

\begin{abstract}
This paper discusses various challenges in remote welding with a surgical robot equipped with a digital camera used to observe the welding zone, in particular the difficulty in detecting the boundaries of the weld pool. The difference in the processing of the real image by the human brain is discussed in comparison with the image in the form of a film from a digital camera. In addition to the need of performing the second derivative of the image in real-time, three models of human recognition of an image were discussed, one of which was already studied by researchers from Cambridge, UK. The concept of melting the base material by bending the weld pool with the pressure of non-ionized arc gases and the American implementation of the measurement of the third dimension of the weld pool and determining the weld penetration by electronics of the welding machine are discussed. Desired movement trajectories of the electrode tip based on the physics of the welding arc and welding technology are presented along with difficulties in teaching the movements to welding trainees. Basics of the neural model of the brain with the vector model of artificial intelligence are also presented.
\end{abstract}

Keywords: remote welding, artificial intelligence in welding, augmented reality, welding mask, weld pool

\section{Introduction}

MAG welder uses one hand in the welding process while TIG welder typically uses both hands, just like a surgeon operating on a patient. There are TIG welding automates with wire feeding, but almost no welder uses it due to decreased ability of dynamic reacting to the welding process. Robots were used in surgeries since the 1990's, first of classical industrial design then redesigned specifically for surgeries, however some robot makers, due to safety and liability concerns, explicitly do not allow use of a welding robot in a cell in presence of people. Because of these constraints, engineers and surgeons had to design specialized robots with sensors, cameras and image processing software, which are not used in industrial robots, but which allow for direct and very fast replication of operators' hand movements. In the 15th century, Leonardo da Vinci conceptualized a mechanical moving robot, which was replicated in 2010. Most commonly used surgical robot, Da Vinci, Fig. 1 [1], made by Intuitive Surgical was used in 2001 to perform a cross-Atlantic surgery via optical cable by a surgeon being in New York and patient in Europe.

Before such long-distance operations were possible, designers of robot Zeus made by Computer Motion who had experience with robots for spacecraft repairs in tight places where astronauts could not reach, developed movement and feedback technology adequate for surgeon's needs. Since late 1990, Institute for Joining of Metals in Krakow used experience and knowledge of astronauts' trainers in the process of teaching welding with a drastically reduced time frame.

Why then despite these successes and successful uses of plasma guns for cutting and osmotic welding of live cells by military medics in Ukraine and USA, such robots are not used for long-distance welding and long-distance training of welders?

In this paper, we present a welding mask with augmented reality based on mental processing capability of a typical welder who observes important parameters of the welding zone through the mask and by analysis of a detailed sequence of welding process film. 


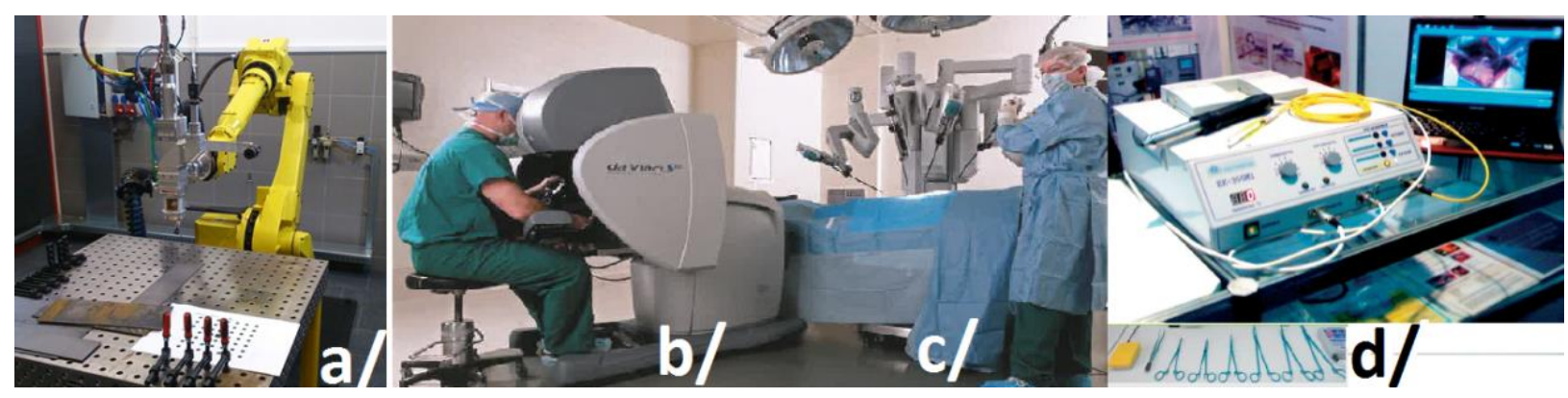

Fig. 1. Real-time manipulation in 3D space using imaging for industrial robot and Da Vinci surgical robot for: a/ distance welding of metals, b/ Da Vinci console [1], c/ Da Vinci end-effectors [1], and d/ welding of living cells using electro-osmosis [2].

\section{New methods of computer image filtration using the augmented-reality welding mask}

Let's imagine the scenario of introducing in front of welder's eyes a computerized digital display in place of a welder's mask filter. Introduction of a digital camera as an element that observes the welding area and a digital monitor as a place where the welder observes the effects of his/her work have already led to the possibility of computerized processing (including digital filtering) of images obtained from the camera before presenting them to the eyes of a human welder who directly controls movements of a welding torch, or to a welding robot operator who in real-time adjusts volts, amperes and movement speed of welding robot arm (welding speed). The methods of computer image filtration are described, among others, in the book [3]. However, it is worth pointing out several goals and several methods of computer image processing, including image filtration, which can be particularly useful in the task of improving the observation conditions of the weld pool and the overall welding area which includes a liquid metal pool (the weld pool), welding groove, newly formed weldment layers and heat-affected zone.

The first task which can be entrusted to a computer image processing system is to improve the image quality and to remove interference from the welding process, such as welding arc or flame of the burner and immense difference in luminosity of the arc or flame and the surrounding areas. By observing the image through a traditional welding self-darkening optical filter, the very bright sources of heat in the welding area cause even darkening of the image which consists of both: the image of the arc (or flame) as well as the weld pool and surrounding it significantly darker other parts of the welding zone. As a result of the simultaneous darkening of the entire scene of the work zone, the arc or flame do not cause instantaneous blinding of the welder's eyesight, but at the same time what should be accurately observed (the place of weld formation) has noticeably worse visibility to the welder, which may adversely affect the accuracy of the welder's work. When between the source of the image capture (digital camera) and the place of the image presentation (the display intended for the welder) a computer equipped with software capable of superfast digital image processing is introduced, it is possible to use algorithms which augment or suppress brightness in various areas of the image thus differentiate it for practical use of the welder. This will result in arbitrary suppression of the glow of the welding arc or flame so that even minor changes in brightness within the pool of molten metal and the area of weld formation can be observed by a welder and used in the process. In particular, the image processing methods such as histogram balancing techniques can be used for this task to focus locally in the sense of individual regions of the welder's field of an image being viewed at any given time. At present, such image processing algorithms are used in highend digital cameras and mobile phones to enhance images containing sharp bright-to-dark transitions in order to overcome shortcomings of CCDs and render images similar to what is formed by the human brain. This is to mimic the fact that an image formed and understood by the human brain is more a result of image processing by a biological computer rather than a raw image captured by human eye optics. For example, in conditions of very low light, humans tend to move their head and/or eyes thus creating several images which are subsequently processed by the brain and combined into an image containing the information of interest.

Another method of computer image processing that can be used when filtering an image observed and used by a welder is related to the possibility of non-linear transformation of the amplitude of the video input signal before it is presented to the welder on the output display. Typical optoelectronic transducers (usually CCDs) used in digital cameras allow for mapping the brightness of each point (i.e. at every pixel in 
the image separately) with an accuracy of at least eight bits. At this amplitude resolution (one byte per pixel), the camera is able to register $2^{8}=256$ distinguishable brightness levels, while human psychology studies show that the welder can visually distinguish at most 60 levels of brightness [3]. Properly choosing an algorithm of transforming 256 levels of brightness of each pixel recorded by the camera (usually via a nonlinear transformation) into less than 60 levels of brightness presented on the display monitor can be accomplished by differentiating the levels of brightness in a manner noticeable to the human eye. Thus, even small changes in brightness which carry information about the border between the pool of liquid metal (welding pool) and immediately adjacent non-molten base metal (both having the same temperature as they are at phase transformation stage) could be noticed. These brightness changes may be imperceptible to humans, so a welder observing the welding process via a digital image processing system could get significantly more information than if he or she observed the process directly, even though the most advanced filters used in a welding mask.

Digital image processing, gives additional possibilities, related to among other things, automatic determination of the boundaries of visible objects (e.g. a drop of liquid metal) and the boundaries of connected elements which are not possible with present-day analog image processing (similar to the biological system used by humans). These boundaries and edges observed with an eye protected by suitable filters often have a fuzzy or blurred character due to indistinguishable differences in emission from liquid metal and solid metal, both at the phase transformation temperature, the high temperature prevailing in the welding zone and the associated observation difficulties. However, researchers dealing with computer image processing have found methods to improve the quality of such images. The whole set of such methods can be found, among others, in the doctoral dissertation [4]. An in-depth scientific study on these methods (allowing even the location of object boundaries with sub-pixel accuracy) can be found in [5]. Connecting the real image of the welder's work area with the results of its advanced digital processing (for example with algorithms to locate borders and detect edges) may, therefore, be accomplished using the augmented reality technique, in which before the image is presented to a human welder, graphic elements (such as lines) resulting from the above-mentioned processing are added to the image to enhance the human perception of the object of interest (e.g. boundary of weld pool). Augmented reality gives also the ability to add text elements to the image. Thanks to these possibilities, along with image filtering techniques which could be employed in a welding mask with computer spatial image processing instead of welding filters only, advanced image analysis techniques are possible and could be used in real time. It is also possible to inform the welder of real-time measurement results of various linear and surface dimensions visible in the image of various welding zone elements, and via calculations of estimated volumetric dimensions. This will lead to a possibility of real-time detection of instances of undesirable welding conditions, for example too fast or too slow movement, with the generation and display of warnings and/or suggestions on the welder's screen, and even to enhance them with graphics helping the welder to take corrective actions in real time. The possibility of displaying such information could be used for training of a novice welder on site or via distance connection. Such possibilities were already explored and implemented in robots used for rehabilitation of injured humans [6].

\section{Welders training - coordinating theory and movement with real time observation}

Training welders is a difficult and time-consuming task with a huge potential for improvement. Fig. 2 shows how it is done traditionally today using welding instructions via schematic picture representation.

The method developed by the Institute of Joining of Metals which proved that problems in instruction originate at the subconscious memory of welding trainees who naturally use principles of physics of water familiar since childhood and engrained in human behaviours through everyday life. This results in psychological inertia during training demonstrated by continuous forceful working against movements of instructor guiding trainees' hand. If the welder is trained in strong emotions (e.g. positive emotions such as admiration for the instructor, or negative emotions such as stress due to fear of failing tasks, or stress associated with learning theory in a form of learning a foreign language based on relevant technical texts in foreign language), then the theory influences practice and the trainee does not fight the trainer. Another aspect of a welder's training is the use of graphical language with physics of metal melting and physics of electric arc hidden in the pictures (similar to theology written in Byzantine icons) then instructor's commands are followed much better. 


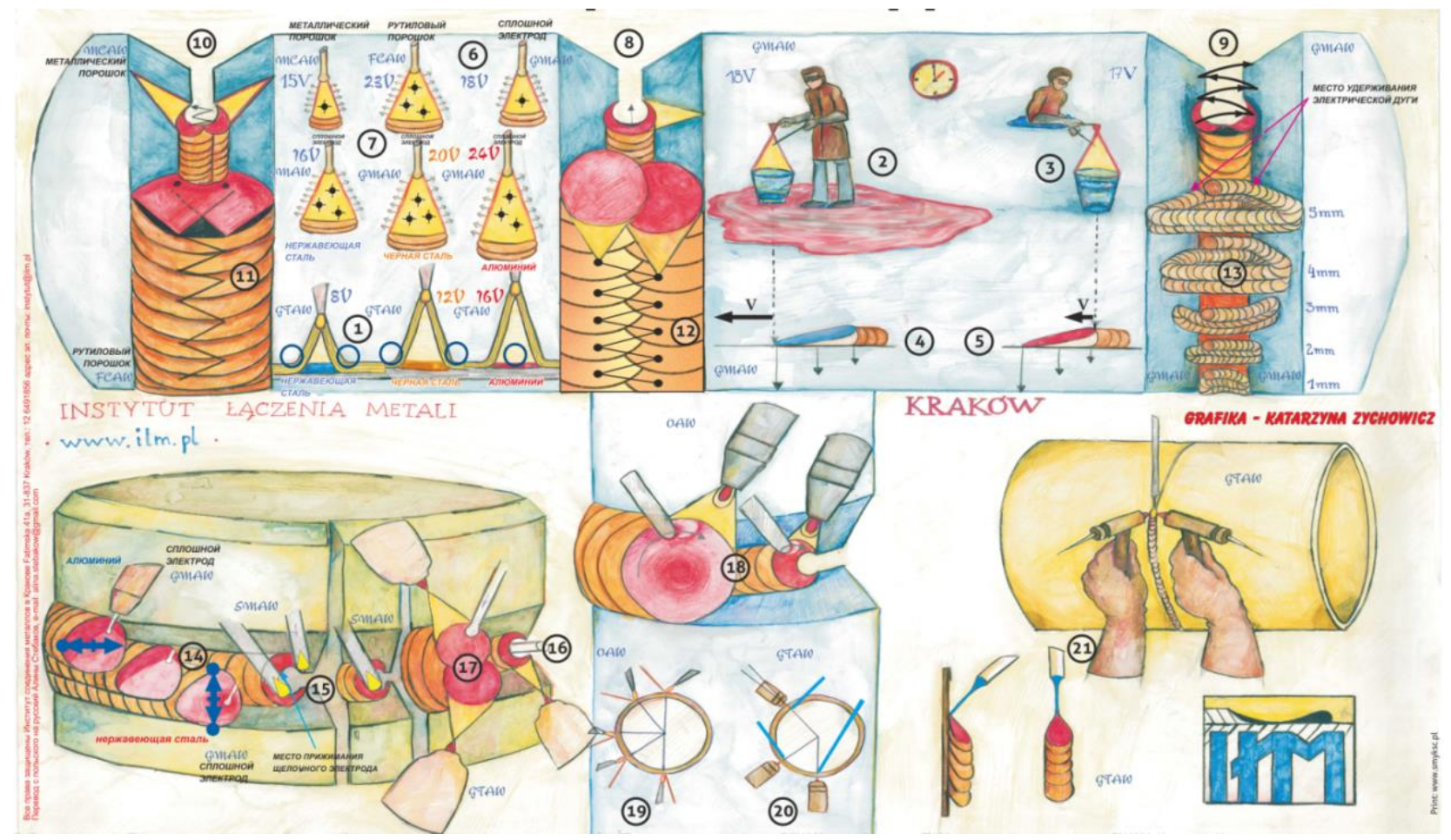

Fig. 2 Welding instructions via schematic picture representation (section numbers are encircled): for $\mathrm{MCAW}=138(\mathrm{EN})$ - section 10; for FCAW = $136(\mathrm{EN})$ - section 11; for GMAW = 135 and 131 (EN) - sections 8, 9, 12, 13 and 14; for SMAW = $111(\mathrm{EN})$ - section 15; for OAW = $311(\mathrm{EN})$ - sections 18 and 19; for GTAW = 141 (EN) sections 1, 16, 17, 20 and 21.

Specifically, these figures are useful in instruction of welding physics for training welders who exhibit traits of strict mind, such as mathematically gifted persons (typical among engineers). It turns out that by giving welding trainees oral commands in the field of welding techniques, it becomes possible not only to train welders, but also to subconsciously program them to coordinate electrode tip movement with observation during welding. Using these pictorial descriptions, an instructor can perform algorithms of "telling" the welder what moves have to be made to improve the welding technique. In a lecture delivered by the Institute of Joining of Metals in Krakow for International Institute of Welding (IIW) in 2002 in Paris, we presented how the predisposition of a human to weld has strongest relation to his/her predisposition for detecting a welding pool boundary. British researchers fascinated by this method which focused on training computers by using detection of a welding pool boundary via video camera and comparing the recorded image to a standard image of the welding pool boundary using cognitive psychology. The problem at the time was the capability of available cameras and image processing equipment to detect the boundary of a welding pool which a typical camera was not capable of detecting, but they were already capable of analysing images captured by moving robots[7]. Example (1) in Fig. 2 (shown with encircled numeral 1) illustrates the depth of welding penetration depending on the distance of the tungsten electrode tip (heat source) and shows that in order to obtain deeper penetration one should shorten the welding arc by bringing the electrode closer to the welding pool (lowering the voltage to 8 Volts is the result of this action). Bringing the heat source closer to the molten metal reduces the temperature of the liquid metal by taking away from the weld pool the heat needed for melting the base material due to contact of non-ionized hot gas of the welding arc with the base material. Moving the heat source (electrode tip) away heats up the weld pool by increasing the area of the weld pool and reduction of the pressure of non-ionized hot gases of the welding arc which are bending the weld pool. Examples (2) and (3) (shown with encircled numerals 2 and 3) illustrate that the large weld pool (lake) is "shallow" and "hot" (i.e., it has a high temperature which is much higher than the melting temperature of the base material), while the small weld pool (lake) is "deep" and "cold" (i.e., it has a lower temperature which is closer to melting temperature of the base material). Examples (4) and (5) (shown with encircled numerals 4 and 5) illustrate that a faster movement of the heat source causes deeper penetration and cooling down of the weld pool by taking away melting heat of the base material; while a slower movement of the electrode results in bending larger amounts of the molten metal with the non-ionized hot gases of the arc hence shallower penetration of the base material which in turn cause slower evacuation of the melting heat thus higher heating of the weld pool (principle of 
conservation of energy). Therefore, while welding with higher amperage one should make faster side-toside movements while welding materials of lower thermal conductivity (e.g. steels, nickel alloys, titanium alloys), and faster forward-and-backward movements while welding materials of higher thermal conductivity (e.g. aluminium and copper). While welding with lower amperage the welder must make respectively slower side-to-side or forward-and-backward movements which are both illustrated in example 14 of Fig. 2.

Examples (1) and (14) illustrate that while welding stainless steels (material with relatively low thermal conductivity) a "cold" drop of metal should be added on the sides of the weldment in order to stop melting the base material thus promoting better heating of not yet molten base material by prolonging the time of heating which is the result of lowering the temperature of the weld pool preventing outflow of the molten metal, especially in vertical and overhead positions. This results in better wetting of the base material with the already molten material of the weld pool and avoidance of welding undercuts. However, in the case of welding aluminum (metal with high thermal conductivity), the wire should be added in the center in the weldment in order not to stop melting of the base material and to cool the center of the weld pool (place of the hot weld pool where the relatively cold liquid droplets are continuously added). This lowers the temperature gradient between the center and the sides of the weld pool which in turn creates lowering of the gradient of surface tension forces thus slows downmixing of the weld pool material (which consists mostly of molten welding wire [8]) with an already molten base material. This results in a difference in the direction of the electrode motions when welding steel with both GMAW methods [9], MAG or MIG, (side-to-side movements), and when welding aluminum with the MIG method [10].

\section{Welding mask with computer spatial image processing as a trainer for coordinating movement with observation}

The implementation of a welding mask with computer processing of a spatial image gives the possibility of a real-time comparison in Mahalanobis statistical space of movements of the trained welder together with main parameters of the welding process (voltage, amperage, and components of the electrode movements such as speed and direction[11]) with computer pre-recorded images and video sequences when the practiced activity was performed by an experienced welder (an instructor or a master to be imitated) [12]. In the case of the system described here, the computer supports the process of continuous observation of the trainee's actions using the techniques described above and can signal detected deviations from the optimal movement and process parameters by comparing the trainee's actions with the previously recorded actions of a master welder. In order to fully utilize the capabilities of this training method, it would be helpful to use artificial intelligence algorithms presently utilized in medical radiography. Information about detected irregularities can be displayed in text aided by appropriate graphics on a trainee's monitor, on which he or she independently follows the previously stored master technological process and the effects of his own actions, which constitutes augmentation of the reality created and observed by the trainee. It is also possible to add real-time warnings about the depth of penetration by using a speech synthesizer attached to the computer.

The elements of artificial intelligence based on neural networks, can be adapted to various types of human abilities while working together with a computer according to the below-described translation of pedagogical concepts into vector mathematics. However, there are other methods of extracting from human sub-consciousness the algorithms of real human intelligence. Since the human brain is not only a consciousness which is a creative one, but also a sub-consciousness which orders problems for execution using common logic of action according to earlier learned algorithms. An example of such a sub-conscious algorithm may be one of the Japanese technical metaphors related to the description of electric current and voltage: "electric water flow" and "electric water pressure". In human consciousness this metaphor is illogical, but it has a mathematical sense because the same equations govern the flow of water and electrical current. The same equations give the same solutions, although their interpretation is different, depending on the scientific field they are used in. In an attempt to decode the logic of unconscious action to recognize microscopic structures by a computer, the Institute of Joining of Metals in Krakow (ILM) analyzed words repeatedly used by laboratory personnel as metaphors known from the linguistics. According to a linguistic theory developed in Poznan, Poland, and in Australia, metaphors can be represented as vectors hence mathematical operations can be performed on them. Through statistical analysis of repeating words from about 700 statements of students with different inherited and learned abilities and combining these words into semantic sets grouped and charted by the above described abilities, ILM came to the conclusion that for example in the Polish language the austenite should be called steel ice (meaning a structure which was 
formed immediately after solidifying the liquid), and the ferrite should be called dehydrated and cracked clay (meaning a structure tight and resistant to corrosion caused by gases but not to corrosion caused by liquids). Austenitic steel is resistant to corrosive acids (according to ASTM nomenclature steels: 302, 304, 308 and 316) and ferritic steel is resistant to corrosive gases (according to the nomenclature ASTM steel 430).
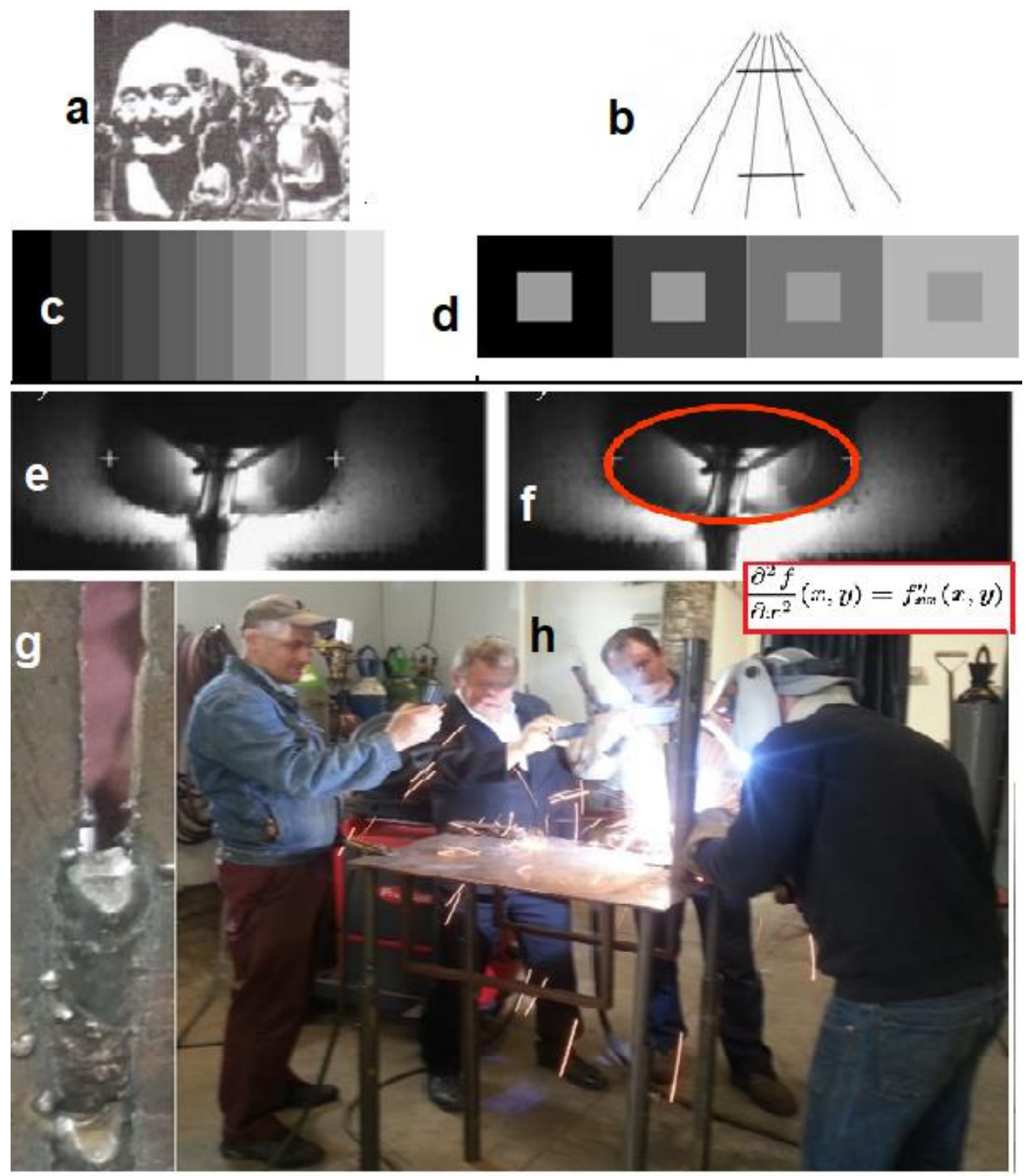

Fig. 3 Properties of image evaluation and futuristic smartphone camera view of 138 flux-cored wire welding covering the weld root side during welding training using Polish instructional method TKS. a/ image decompression and composition, b/ seeing in perspective, c/ edge detection, $\mathrm{d} /$ perception against the background, e/ smartphone sees blurry image hence its users are not able to use its information in real-time, $\mathrm{f} /$ biological human computer takes the second derivative of the image thus sees boundaries of the g/root pass, h/ futuristic smartphone camera view of 138 metallic flux-cored wire welding

By comparing registered movements of a robot and master human welder, and proceeding similarly, we can obtain desired metallurgical structures by controlling movement trajectory and dynamics of the welding electrode tip and suitable bending of the weld pool; all despite the lack of adequate mathematical description of welding phenomena (model of point heat source used in ISO15614 is largely inadequate).

A human sees more with the brain than with optics, therefore an aborigine who throws a boomerang at an animal performs very complicated mathematical operations with a subconscious biological computer that cannot be accessed by a slow-acting conscious computer used for logical thinking. Therefore, if a person observes the area of welding through a camera, the person does not see the image in a continuous way, but rather as individual frames only, and this limits the amount of work done by the subconscious brain. As a result, this activity unnecessarily utilizes the conscious brain power to put these frames in one 
model. Consequently, a person (a welder) is not able to process the image observed on a mobile phone as a welder who is looking directly at a weld pool (Fig. 3).

The whole training process can be followed on additional monitors by one or several instructors who can add their advice during the welding process or after some completed stage of a series of scheduled training. The level of difficulty of this undertaking can be viewed through the prism of non-existent smart phone cameras and software capable of accomplishing such tasks. A variety of documentation can be automatically prepared from such training sessions and stored. Such documentation can also be utilized for quality assurance purposes, mistake proofing and error finding in case of failures of weldments.

\section{Methods of 3D analysis of crystalizing weld pool using a computer-assisted analysis of image obtained from a digital camera}

During our presentation at IIW in Paris in 2002 we showed that the effectiveness of developing a welder's ability to weld is based on developing the ability to detect boundaries between the liquid phase and the solid phase in a welding pool. On the boundary, there is the same material at the same temperature, but due to the difference in thermal convection between the metal's liquid phase and solid phase, there is a difference in speed of increase of the light intensity emitted by each phase. However, performing a second derivative of the image, which detects the boundary between liquid and solid phases (weld pool boundary), was impossible to do in real time in 2002 due to a lack of computational speed of commercially available computers.
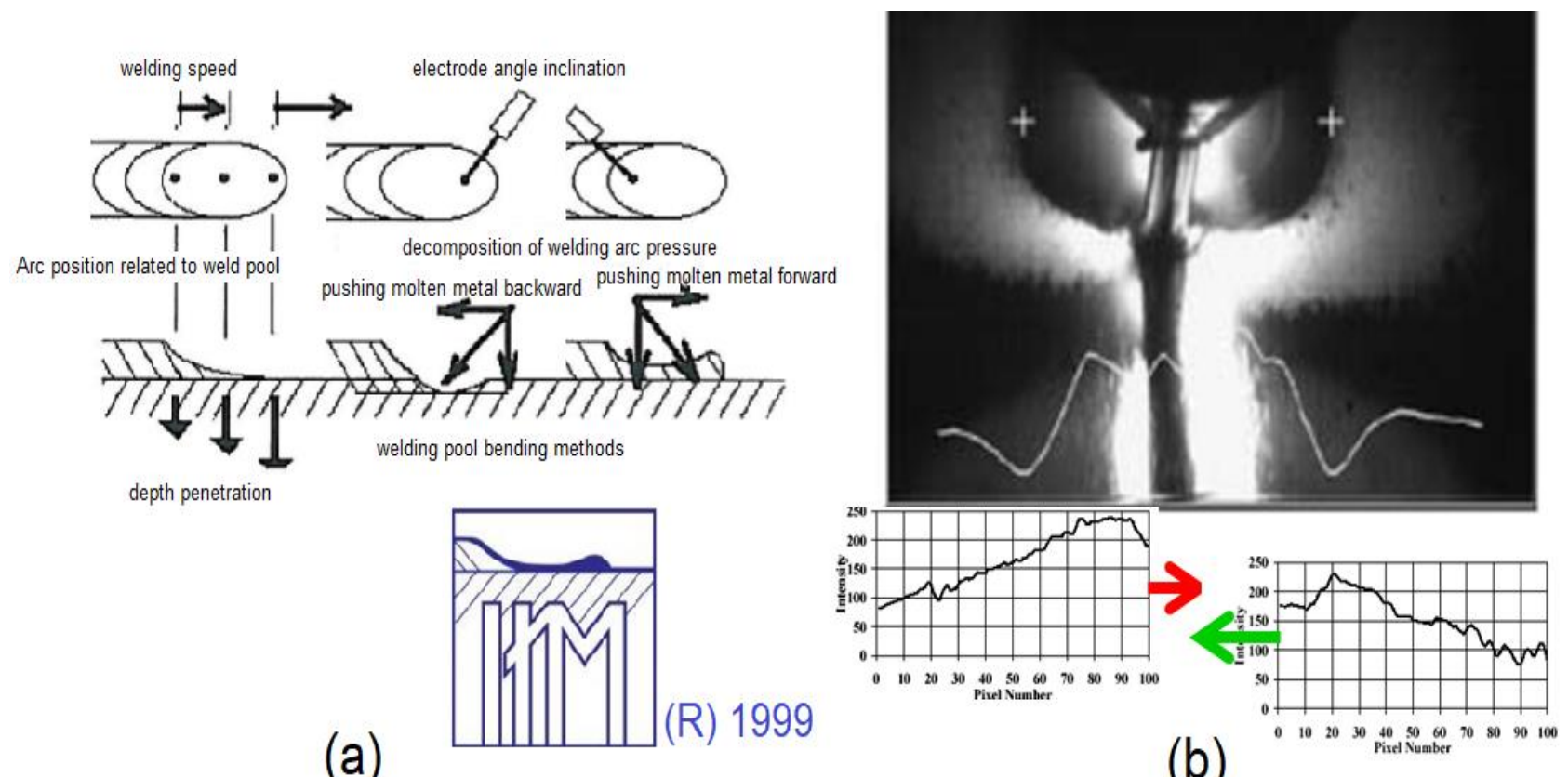

Fig. 4 a/ Polish theory of welding process presented in Cambridge, UK in 2004, b/ British method of finding welding pool edge via comparison to the template presented in Cambridge, UK in 2004 [10]. Left plot moving by one pixel to the right and calculation of the sum of differences between the template and the light source. Right plot moving by one pixel to the left and calculation of the sum of differences between the template and the light source

To understand the physical characteristics of the electric arc used for welding it is relevant to show its macroscopic view as well as explain how it creates. Initiation of the electric arc occurs as a result of physical contact (short-circuiting) of the two electrodes connected to a power source, which results in heating the region of electrodes being in contact with each other. Also, it is possible to initiate the electric arc in the non-contact technique using the ionizer. The heat released at the electrode tip (e.g. tungsten, $\mathrm{W}$ ) leads to the thermionic emission of negative charge from this region. Then, the electrodes shall be forced apart and the electric field is created in between. The emitted electrons (-) from the cathode move into the direction of the anode (+). Simultaneously, the electrons during moving into the direction of anode impact the Ar atoms causing their ionization $\left(\mathrm{Ar} \rightarrow \mathrm{Ar}^{+}+\mathrm{e}\right)$. As a result of this phenomenon, between two electrodes peculiar matter - plasma - is formed, having features of the solid. The arc plasma is a mixture of free electrons and ions which demonstrates the capability to conduct the current. After reaching the electrode the charged 
particles release the energy required to melt the base material. Ar+ ions, after rebounding off the ions from the base material, move into a direction of the anode W (-). Part of them, which found in the outer zone of the plasma, recombinase and reverse to the normal state.

Fig 5. depicts the temperature distribution in plasma arc formed in Ar noble gas in the systems: a tungsten electrode-stainless steel (W - 1H18N9T, Fig. 5a [13]) and a tungsten electrode-copper (W-Cu, Fig. $5 \mathrm{~b},[14])$. It is visible, that in both cases the differences in temperature are significant in both longitudinal and transverse direction of the arc plasma. In the case of both metallic electrodes (Fig. 5a, b), with negative polarity at $\mathrm{W}$ electrode and direct current applied, the temperature near cathode is about $20000 \mathrm{~K}$, whereas near anode it is about $9000 \mathrm{~K}$. The highest temperature occurs in the region of the greatest "compression" of the arc and constitutes the smallest region. Generally, the temperature of the arc plasma depends on the type of the gas, the arc length, and type of the electrode. The gas that characterizes by the higher ionization energy (e.g. He) gives the higher temperature of the plasma arc.
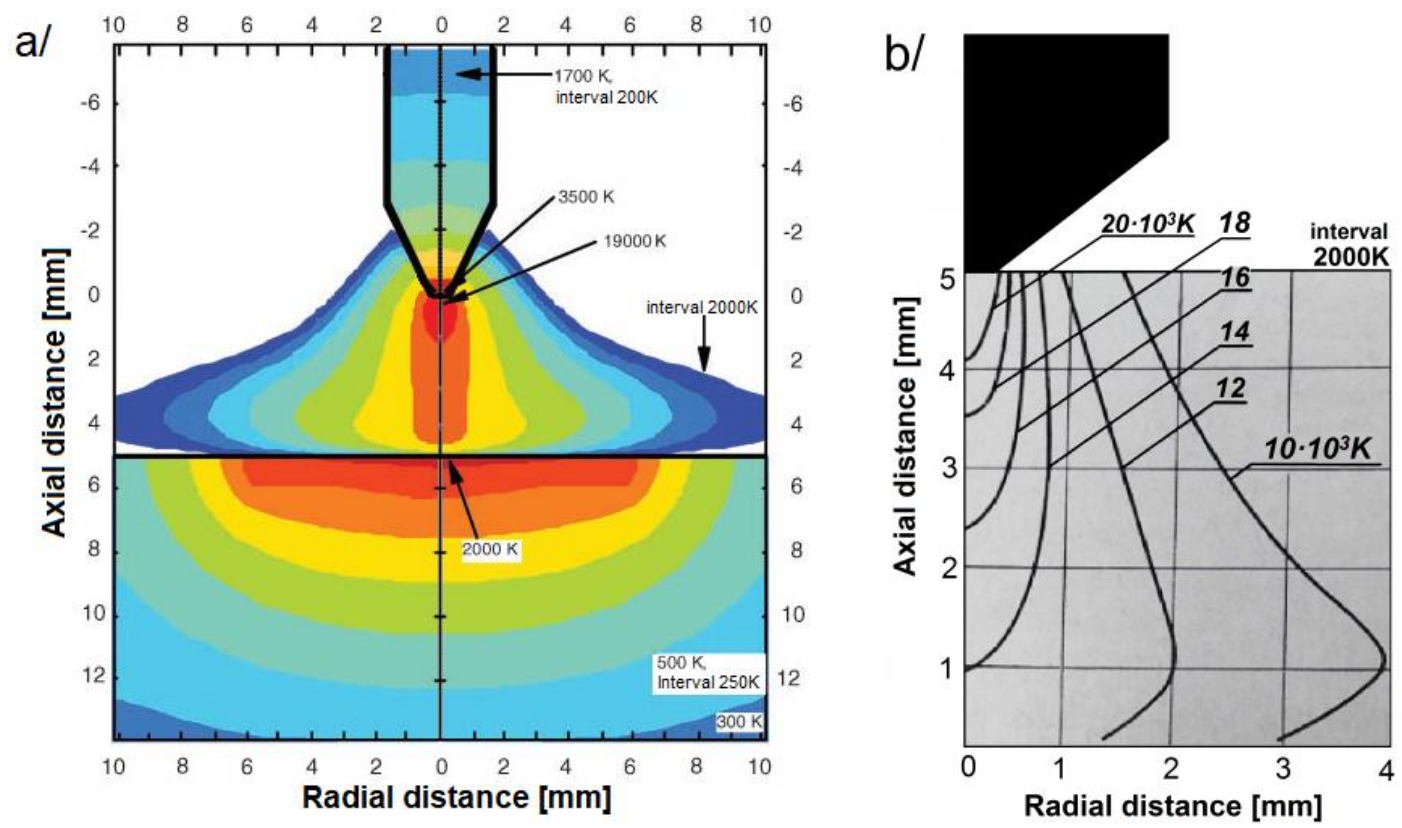

Fig. 5. Schematic view of arc plasma for TIG welding, in Ar atmosphere, for the metal systems a/W-stainless steel (1H18N9T) [13], and b/W-Cu [14]

As long as the plasma generated between metallic two electrodes is well recognized in literature, the knowledge about the plasma created in the system metallic electrode-ceramic materials is deficient. Fig. 6a illustrates the real view of the plasma between the tungsten electrode and ceramic material [15]. The showed plasma arc was observed during the synthesis of refractory spinel materials resistant to high temperatures in Arc Plasma Furnace $\left(\mathrm{FeAl}_{2} \mathrm{O}_{4}\right.$, hercynite, Fig. 6b). What is distinctive here, from the macroscopic point of view, is the different shape of the arc plasma compared to metallic system. In contrast to the "pear" shaped arc for two metals, here it is more elongated. Also, temperature zones are clearly visible. The view of the plasma arc, Fig. 6a, demonstrates five temperature zones of the plasma arc, based on different optical density, that were marked as 1-5. The zone designated as 1 constitutes the most inner zone of the arc plasma of the highest temperatures created by the ionized argon of the greatest energy. The zone designated as 5 shields the melted region and characterizes by the lowest temperature in which recombination of argon ions proceeds. The presented experience-based knowledge can be applied in the creation of the intelligent computer systems for long-distance joining of both metal-metal and metal-nonmetal systems [15]. 

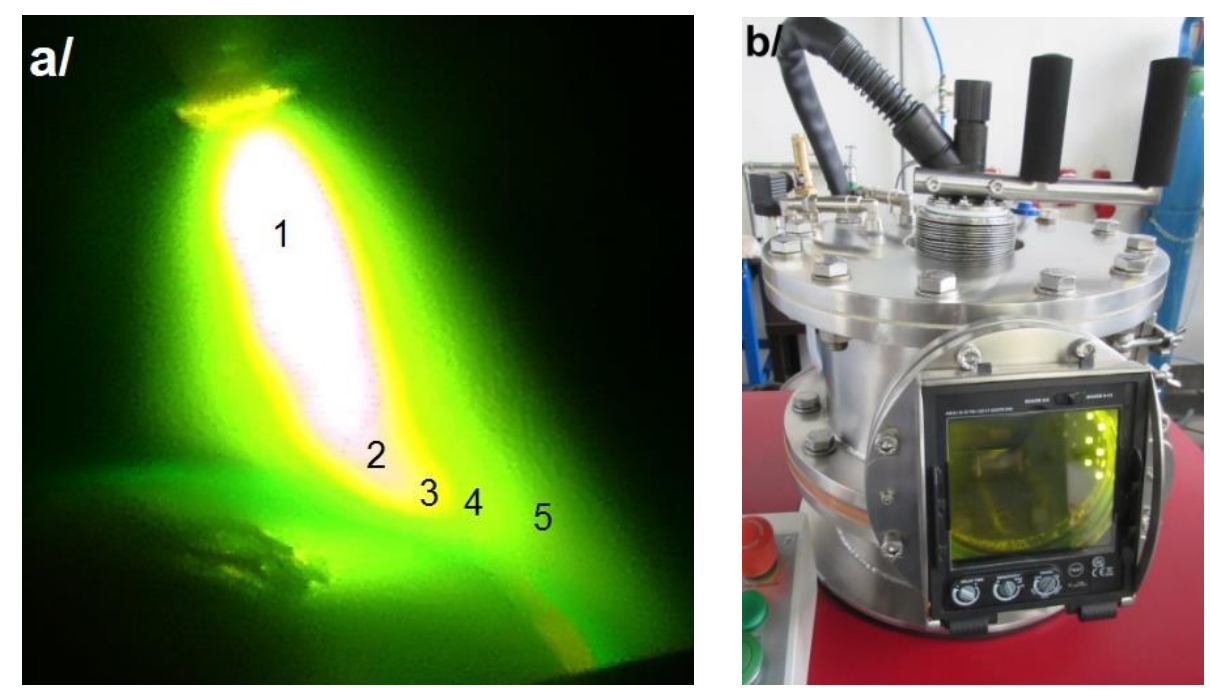

Fig. 6 a/ The actual view of the arc plasma created in Ar atmosphere in the system Cu-ceramic refractory material $\left(\mathrm{FeAl}_{2} \mathrm{O}_{4}\right)$, b/Arc Plasma Furnace (SpekoArc300) for production of high-purity ceramic refractory materials (AGH, Department of Ceramics and Refractories) [15]

Cognitivist theories of image identification may add vital information to the characteristics of cognitive processes playing active roles in the welding operation. Therefore, we drew attention to 3 different models of image identification and subsequent analysis which may be used in welding [16].

1. Comparison with the original pattern. The simplest model in which the key term is "original pattern". The identification is based on matching the incoming signal (image, pattern, a sequence of images, moving images) with the already stored original signal (image, pattern, a sequence of images, moving images). To find a signal (e.g. a pattern) which matches the original signal better than the other incoming signals means to identify the signal.

2. Pandemonium - the system of subconscious functioning consisting of numerous succeeding subprograms, often functioning in a cascade of succeeding reactions. The last subprogram/stage consists of decision making based on the intensity of reactions of individual cognitive subprograms. In the 1950s the Pandemonium System was one of the first attempts to build a hierarchical recognition system based on the very same principles as the more recent MLP neural networks have.

3. Analysis by means of synthesis - the sensory data interpretation of the incoming signal is based on the knowledge of what the signal should be. This knowledge is provided by a context of a sensory incident, which is described as a huge load of information stored and usually automatically used for explaining the incidents. This context-based information evokes expectations which focus our attention on certain stimuli and are responsible for their selective reception. This model has an ability of self-teaching therefore it lends itself for use in neural networks and artificial intelligence. Our knowledge about what the image represents accelerates the process of interpretation. If we know what we are looking for, it is easy to find it. The image may also be ambiguous because there are many plausible ways of interpreting it. A person with a predisposition to exact sciences decompresses the image in Fig. 3a, like letter recognition programs, and sees several nuns. Using humanistic skills, we can compose the image so that the nun's faces will form Voltaire's eyes, their silhouettes will make his nose, and the white waists of their frocks - his chin. In nondeterministic software, the most important effort was the Prolog language [13].

The three models differ in the way they deal with difficulties created by the task at hand concerning the processing of data obtained from sensory input (in our case an image of the weld pool boundary and its surroundings). At the end of the data processing, the useful output image is identified. This theory employed in the context of processing the information gathered during an intentional act of welding, the contents, and form of which has been registered, is presented below on the bases of experiences acquired during welder's training. An intelligent welder perceives an image in time and space and complements this image with his knowledge of the physical processes that cause the creation of the weld that the image represents. When we are watching a film, for example, the image we build on the basis of our past experiences, knowledge about the image and previous frames of the film is focused. But when we freeze the frame, we notice that the image is out of focus. 
Intelligent perception consists in analyzing the physically possible changes of the weld pool, which allows us to reject image distortions and select only the information that effectively complements the image. The progress in real-time image processing is limited by the fact that since the beginning of the information era, or the fifties, there have been no significant advances in the following fields: memory semantics of algorithmic systems, the semantics of concurrent processes, and nondeterministic algorithms. It is in these three fields that information science falls behind the solutions existing in nature, namely the nervous systems of living organisms. As for the concept of memory, it should be noted that contemporary object programming does not go beyond the pattern of dynamic allocation of memory in the course of the process, and at the same time memory is allocated in the form of units whose semantics can be reduced to the level of a well-commented code in the assembler.

As for the semantics of concurrent processes, different systems use temporary solutions that are supported by specific program libraries. In nondeterministic software, the most important effort was the Prolog language, whose low practical efficiency due to fundamental principles of the project prevented the application of this type of software in serious industrial projects. There are plans and advanced projects that aim at eliminating these three limitations. In order to speed up work, we must first determine the position of known objects such as the nozzle or the wire tip, remove the elements of the arc, locate the molten pool, and finally analyze the remaining parts of the image. Current computer systems are of no use for that purpose. It is necessary to create new systems based on the methods of research used in the humanities.

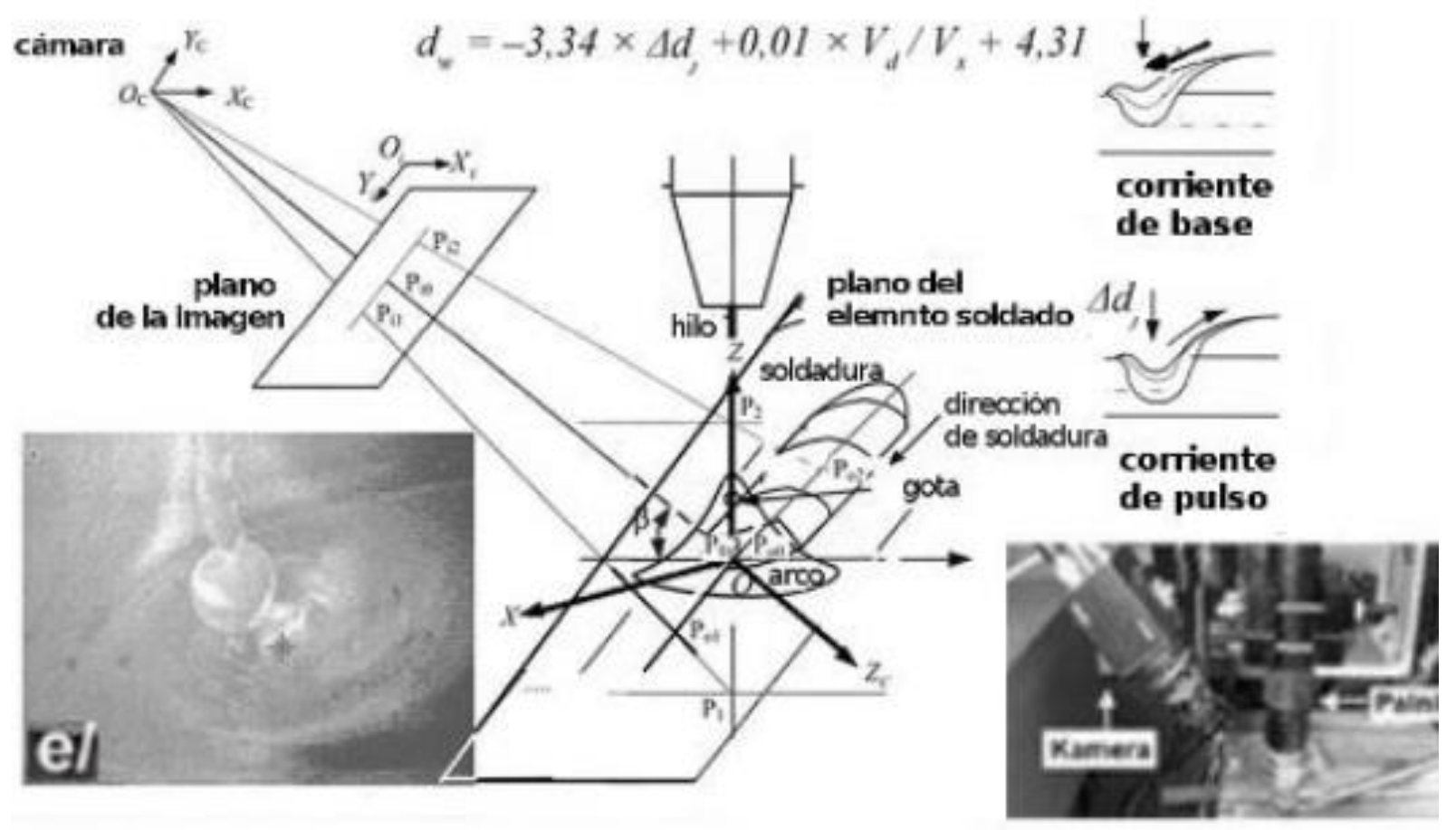

Fig. 7 American method of determining penetration depth by optical measurement of weld pool bend in GMAW pulse welding from 2010

\section{Elements of artificial intelligence in welding with surgical robots}

In biology, there is a theory that a practical brain (e.g. shark) evolved first, then a humanistic brain (e.g. bird) evolved next, and then a creative brain (e.g. human) evolved. There had to be a continuity of brain development to support continuity of already existing life, hence a new type of brain evolved as an addition to the already existing one. From psychology, it is known that man's abilities are not permanent and can be developed or lost because a typical human wants is to achieve satisfaction with the least amount of effort and it depends on the "writing" existing in the brain whether a welder will be left-handed, righthanded or ambidextrous.

Fig. 8 shows a neural model of the human brain with three levels of processing:

- practical mind (shark's brain)

- humanistic mind (bird's brain) 
- strict mind (brain for conscious and creative processing)

To define a practical, humanistic and exact way of processing, a 20 by 5 by 2 neurons model was created along with vectors representing respectively: a number of traits (attributes), intensity of the traits (attributes), and direction of information processing (creative and reproducing/imitating). It is assumed that the mind is a creative one when it processes a large variety of traits (attributes) but the majority of them at lower intensity levels; while a mind is reproducing/imitating when it processes fewer traits (attributes) but each one more accurately. It is also assumed that a person possesses a practical ability when a relevant practical model of information processing is installed on a practical level, a person has a humanistic ability when at the humanistic level the person has a humanistic information processing model installed, and a person has a creative ability when at the strict level the person has installed a mathematical or creative model of information processing.

In Fig. 8 the vector of the number of traits $(X)$ multiplied by the vector of the intensity of a trait $(Y)$ results in direction of information processing (the necessary number of repetitions in the genetic algorithm of neural networks).
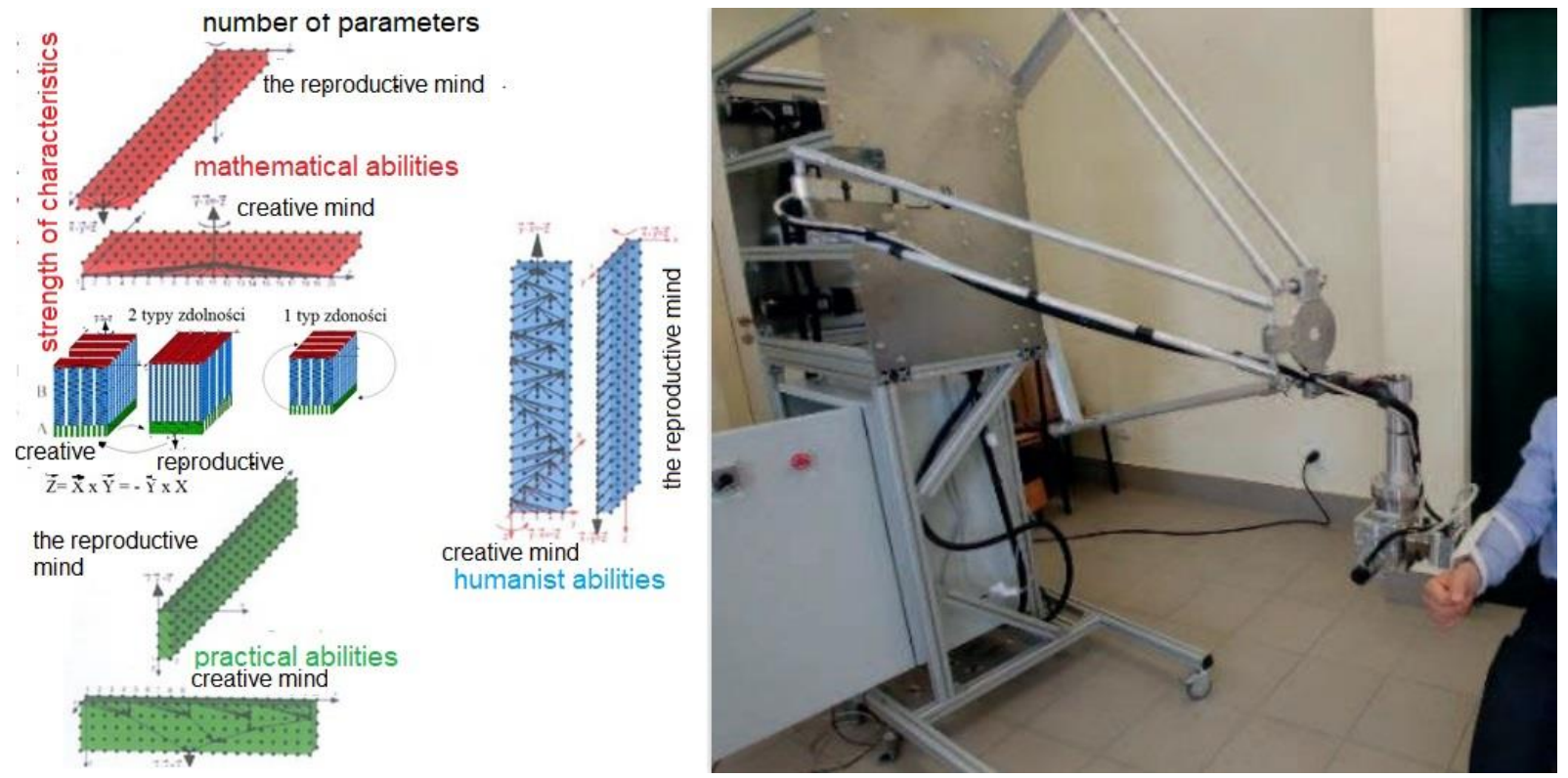

Fig. 8 Vector model of types of abilities shows a neural model of the human brain with three levels of processing, and rehabilitation robot on the right [6]

\section{Application of linguistic knowledge to the analysis of the properties of intelligent information processing}

There are following methods of edge detection in information science: the Laplacian, gradient methods (e. g. by Roberts, Prewitt, Sobel, Kirsch), pyramid edge detection, morphological and frequency methods. Object recognition methods include: nearest neighbor method, $\mathrm{k}$ - nearest neighbor, nearest mode, spherical environment mapping, feature space division, neural networks. The first three are minimum distance methods, the other three are approximative methods. In order to compare the functioning of computer programs and the welder, who recognizes images by comparing their descriptions, it is necessary to employ the concepts of image identification used in linguistics and translation. Linguistics introduced the following concepts to describe images: the dimension of selection (domain, scale and scope), abstraction and perspective, relative salience, and figure/ground alignment. The following concepts are used for object recognition: iconicity, metaphor, epistemic and axiological commitment.

The unconscious level analyzes rapidly changing images, which permits us to change the type of metal transfer and stabilize the arc. Its stability facilitates observation and the making of nice-looking passes. The same automatic adjustment was presented in the study by the Japanese researchers from Nippon Steel Corporation. The current visual systems for welding are the simplest stimulus-reaction systems that focus on the recording precision of the sensor, in this case, a camera. Another issue is the detection of weld pool edges. In the study carried out at the University of Liverpool, a system of comparison with the original pattern was developed to solve this issue. It might be well to consider using 
linguistic and translation knowledge to design programs that describe the image of the weld pool. This type of software should include (be "taught") what technologists refer to as welding abilities. It is the lowest level of information processing, shown in Fig. 8 as automatic processing, or the first stage of work on creating intelligence in welding.

We often speak of borderlines between cultures or epochs. Edge detection is very important in image identification. It is called the effect of brightness contrast, which manifests itself in the form of Mach bands (Fig. 9c). A person can perceive bright and dark bands although there are no physical changes in the intensity of light.

Our evaluation of a person's behavior depends on the background, both in the sense of the circumstances in which we see this person and the total of his or her knowledge, education and experience. Figure $9 \mathrm{~d}$ shows that the difference between an object and a background is also very important in image identification.

In Polish literature, a character's misdeeds analyzed from the perspective of the struggle for independence can transform him into a hero. Fig. $9 \mathrm{~b}$ shows how perspective can influence perception. Because of the presence of perspective in the drawing, two lines of equal length are so analyzed that one appears longer than the other.
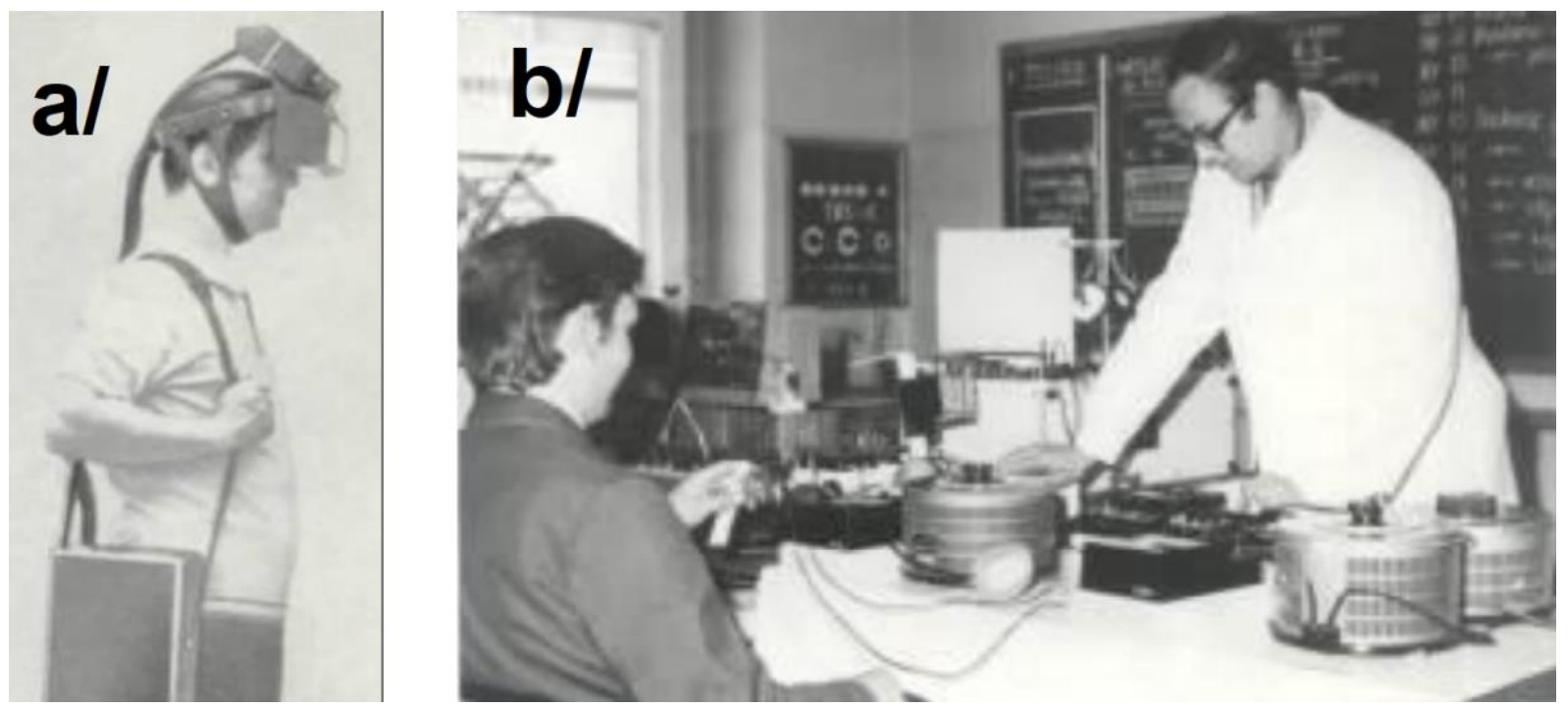

Fig. 9 Polish innovations: a) Elektroftalm - a device for transmitting visual information through vibrations stimulating the skin of the forehead, b) Director of the Bureau of Aviation Electronics Designs in Poznan Dr Mieczysław Cenin during the doctoral examination of the pilot's response time at the electro-touch transmission of visual information to the brain (3 times faster than sight) in 1975.

\section{Conclusions}

Using an augmented reality welding mask will allow for real-time verification of a trainee making the weldment and comparing the process to a master standard. Joining of welding robot equipped with image processing capabilities based on augmented reality display of the welding zone and real-time feedback from welder opens limitless possibilities for remote training, welding work and welding in dangerous environments such as underwater.

Based on the presented possibilities, there is a high potential of remote real-time welding which will cut on the travel needs of highly trained welding specialists. Much work still needs to be done in building the appropriate hardware and software needed for real-time processing of the image of the welding zone and presenting it in a manner useful to the welder, as well as post-process quality control and documentation. In order to perform that well, the in-depth knowledge about the physics of the arc shall be thoroughly understood. Moreover, apart from joining metal elements, also joining metals with non-metals reveals great potential, as ceramics, e.g. UHTC (ultra-high temperature ceramic [17]) exhibits resistance to extreme conditions, thus being in high demand by the advanced-technology industry. Therefore, this area shall be further explored.

Thanks to the ability to register welders' movements, this system will allow for conducting scientific research on the influence of the welder's work movements on thermal processes in welding.

Application of astronaut training methods permits the creation of algorithms that have not been available in computer science so far - the unconscious information processing by the welder. Use of a 
brain-computer touch interface developed for space application introduces an additional stage between hand welding and intelligent vision systems for welding, The properties of the mind make it possible to use linguistic knowledge to write intelligent programs for creating image descriptions based on which the images could be reconstructed and compared.

Author Contributions: conceptualization, R.T. and R.J.; methodology, I.J.; software, I.J.; formal analysis, Z.P.; resources, R.T.; data curation, Z.P.; writing-original draft preparation, R.J.; writing-review and editing, I.J.; visualization, I.J.; supervision, R.J.; funding acquisition, I.J."

Funding: The work was partly supported by the statutory funds of the Faculty of Materials Science and Ceramics at the AGH University of Science and Technology in Cracow, Contract no.: 1616160557.

Conflicts of Interest: The authors declare no conflict of interest.

\section{References}

[1] Dobrowolski Z., Tadeusiewicz R., Robotyka Urologiczna. Kraków, Poland, Lettra Graphic Publ., 2014.

[2] Paton B.E., Krivtsun W.I., Marynsky G.S., Chernets I.Y., Khudetsky Y.N., Lankin S.E., et al., Zgrzewanie oraz obróbka termiczna żywych tkanek prądem o podwyższonej częstotliwości. Biuletyn Instytutu Spawalnictwa, 2014,(5), 92-101.

[3] Tadeusiewicz R., Jastrzębska I., Jastrzębski R., Możliwości stworzenia maski spawalniczej z komputerowym przetwarzaniem przestrzennego obrazu zamiast filtrów spawalniczych. Welding Technology Review, 2016, Vol. 88(1), 17-22. https://doi.org/10.26628/ps.v88i1.558

[4] Fabijańska A., Algorithms of image quality improvement in high-temperature measurements of physico-chemical properties of selected metals and their alloys. Ph.D. Diss. Łódź, Łódź University of Technology, 2007.

[5] Fabijańska A., A survey of subpixel edge detection methods for images of heat-emitting metal specimens. International Journal of Applied Mathematics and Computer Science, 2012, 695-710. https://doi.org/10.2478/v10006-012-0052-3

[6] Łaski P.S., Pietrala D., Delta robot with pneumatic muscles for medical applications. Projektowanie i Konstrukcje Inżynierskie, 2019, Vol. 139(4), 36-41.

[7] Jastrzębski R., Control of MIG/MAG welding machines. Welding International, 2014, Vol. 29(16), 4546. https://doi.org/10.1080/09507116.2014.937592

[8] Chmielewski T., Siwek P., Chmielewski M., Piątkowska A., Grabias A., Golański D., Structure and selected properties of arc sprayed coatings containing in-situ fabricated $\mathrm{Fe}-\mathrm{Al}$ intermetallic phases. Metals, 2018, Vol. 8(12), 1059. https://doi.org/10.3390/met8121059

[9] Wang Z., Zhang Y.M., Wu L., Measurement and estimation of weld pool surface depth and weld penetration in pulsed gas metal arc welding. Welding Journal (Miami, Fla), 2010, Vol. 89, 117-126.

[10] Lucas W., Bertaso D., Melton G., Smith J., Balfour C., Real-time vision-based control of weld pool size. Welding International, 2012, Vol. 26(4), 243-50. https://doi.org/10.1080/09507116.2011.581336

[11] Gontarz G., Golański D., Chmielewski T., Properties of Fe-Al Type Intermetallic Layers Produced by AC TIG Method. Advances in Materials Sciences, 2013, Vol. 13(3), 5-16. https://doi.org/10.2478/adms2013-0007

[12] Sukamu M., Tsuboi R., Kubo K., Asai S., Development of welders training support system with Visual Sensors.In: IIW document or XII-1813-04, Proceedings of IIW Conference, Osaka, Japan, 2004. p. 103-108.

[13] Yamamoto K., Tanaka M., Tashiro S., Nakata K., Yamazaki K., Yamamoto E., et al., Metal vapour behaviour in thermal plasma of gas tungsten arcs during welding. Science and Technology of Welding and Joining, 2008, Vol. 13(6), 566-72. https://doi.org/10.1179/174329308X319235

[14] Olsen H.N., Thermal and electrical properties of an argon plasma. The Physics of Fluids, 1959, Vol. 2(6), 614-23.

[15] Jastrzębska I., Hercynite solid solutions - synthesis, properties and applications. Ph.D. Diss. Kraków, AGH University of Science and Technology, 2017.

[16] Lindsay P.H., Norman D.A., Human information processing. An introduction to psychology. New York, Academic Press, 1972.

[17] Shabalin L.I., Ultra-High Temperature Materials II: Refractory Carbides I (Ta, Hf, $\mathrm{Nb}$ and Zr Carbides).Springer, 2019.

(C) 2020 by the authors. Submitted for possible open access publication under the terms and conditions of the Creative Commons Attribution (CC BY) license (http://creativecommons.org/licenses/by/4.0/). 